\title{
On Forecasting Cointegrated Seasonal Time Series
}

\author{
Mårten Löf*and Philip Hans Franses ${ }^{\dagger}$ \\ SSE/EFI Working Paper Series in Economics and Finance, No. 350 \\ January 2000
}

\begin{abstract}
We analyze periodic and seasonal cointegration models for bivariate quarterly observed time series in an empirical forecasting study. We include both single equation and multiple equations methods. A VAR model in first differences with and without cointegration restrictions is also included in the analysis, where it serves as a benchmark. Our empirical results indicate that the VAR model in first differences without cointegration is best if one-step and four-step ahead forecasts are considered. For longer forecast horizons, however, the periodic and seasonal cointegration models are better. When comparing periodic versus seasonal cointegration models, we find that the seasonal cointegration models tend to yield better forecasts. Finally, there is no clear indication that multiple equation methods improve on single equation methods.
\end{abstract}

Keywords: Periodic cointegration; Seasonal cointegration; Forecasting

JEL: C32; C53

\footnotetext{
${ }^{*}$ Department of Economic Statistics, Stockholm School of Economics, P.O Box 650111383 Stockholm, E-mail: stmlo@hhs.se. (corresponding author)

†Econometric Institute, Erasmus University Rotterdam, P.O. Box 1738, 3000 DR Rotterdam, The Netherlands.
} 


\section{Introduction}

In recent years several methods for cointegration analysis of nonadjusted seasonal time series have been developed. If one is willing to assume that the seasonal pattern is approximately constant over time, the vector autoregressive error-correction model $[\mathrm{VECM}]$ with constant seasonal dummies parameters can be used. However, tests for various types of changing seasonality oftentimes find evidence for a stochastic or changing seasonal pattern over time, see Hylleberg et al. (1990) [HEGY], Franses (1996), among many others.

In this paper we examine in an empirical forecasting study the relevance of taking care of changing seasonality within multivariate methods for cointegrated seasonal time series. We evaluate three different approaches, see Franses and McAleer (1998), that is nonseasonal cointegration models, seasonal cointegration models and periodic cointegration models.

Testing and estimating seasonal cointegration relations can be accomplished in at least two ways. Engle et al. (1993) [EGHL] propose a two-step procedure, which is an extension of the Engle and Granger test for cointegration, whereas Lee (1992) suggests a maximum likelihood method for seasonal cointegration, using a seasonal error correction model. Johansen and Schaumburg (1999) introduce a general asymptotic theory for the latter cointegration approach. While cointegration at the zero frequency can be interpreted as evidence of a parallel long-run movements among the time series considered, cointegration at the biannual or annual frequencies is viewed as evidence of parallel movements across the corresponding seasonal components of the time series.

An alternative model for changing seasonality in multivariate data extends the periodic integration model, see Franses (1996) and Boswijk, Franses and Haldrup (1997), among others. When the individual time series display periodic features, one may want to consider periodic cointegration. A useful single equation method is proposed in Boswijk and Franses (1995), and it is an extension of the cointegration test approach by Boswijk (1994). A multiple equation method is proposed by 
Kleibergen and Franses (1999), who consider cointegration in periodic VAR models [PVAR].

The forecasting performance of seasonal cointegration models has been analyzed in Kunst (1993) and in Reimers (1997). Two examples based on real data and a Monte Carlo experiment in Kunst (1993) indicate that the benefits from accounting for seasonal cointegration are quite limited as compared to vector error correction models in first differences with deterministic seasonal dummies included. The main conclusion in Reimers (1997) is that models in first differences produce smaller forecast errors for short horizons, but when longer forecasting periods are considered the seasonal cointegration model appears preferable. Finally, the forecasting performance using different specifications of the single equation periodic cointegration model has been examined in Herwartz (1997), where it is found not to be very successful.

The purpose of the present paper is to compare the two model classes in an empirical forecasting study, which involves seven sets of bivariate quarterly time series, which one may expect to be somehow cointegrated. We aim to shed light on the following issues. Do multiple equation methods for seasonal and periodic cointegration generate better forecasts as compared to their single equation counterparts? And, is one of the two model classes, that is seasonal versus periodic cointegration, preferable in terms of forecasting? We also compare these periodic and seasonal cointegration models with a VECM in first differences with constant seasonal dummy parameters and with an estimated long-run relation included. Finally, we also include a VAR model in first differences with constant seasonal dummy parameters in the analysis, that is, a model without cointegration.

The remainder of this paper is organized as follows. Section 2 gives a brief discussion of the various cointegration approaches. In Section 3, we present the data and Section 4 contains the estimation and forecasting results. The final section presents some concluding remarks. 


\section{Cointegration methods}

In this section we review four different approaches to cointegration analysis of quarterly time series. Later on, we will contrast these approaches with a VECM with constant seasonal dummy parameters, where the long-run relation is estimated from the data for the bivariate series at hand (denoted as N-ME-1, which means nonseasonal multiple equation of type 1), and with a VAR model for first differenced variables without cointegration, also with constant seasonal dummy parameters (denoted as N-ME-2).

For some methods it can be useful to examine the properties of the univariate time series first. For this purpose one can use for example the HEGY (1990) testing approach for seasonal unit roots, and the Boswijk, Franses and Haldrup (1996) testing approach for unit roots in periodic models. These methods are now well known by now, and a detailed outline is considered to be beyond the scope of the present paper.

We now turn to the various cointegration methods, where we deal with periodic models first and with seasonal cointegration methods second. Within each class, we first deal with the single equation approach and then with the multiple equation method.

\subsection{Periodic cointegration - single equation}

The Boswijk and Franses (1995) approach is an extension of the cointegration test approach in Boswijk (1994). They consider the following single equation periodic cointegration model $[\mathrm{PCM}]$ :

$$
\begin{aligned}
\Delta_{4} y_{t}= & \sum_{s=1}^{4} \mu_{s} D_{s, t}+\sum_{s=1}^{4} \lambda_{s}\left(y_{t-4}-\theta_{s}^{\prime} X_{t-4}\right) \\
& +\sum_{j=1}^{p} \beta_{i} \Delta_{4} y_{t-j}+\sum_{i=0}^{p} \tau_{i}^{\prime} \Delta_{4} X_{t-i}+\varepsilon_{t},
\end{aligned}
$$

where $y_{t}$ is the variable of specific interest and where $X_{t}$ is a vector of explanatory variables. The $\varepsilon_{t}$ is a standard white noise process and $\Delta_{4} y_{t}$ is defined by $\Delta_{4} y_{t}=$ $\left(1-B^{4}\right) y_{t}=y_{t}-y_{t-4}$. It is assumed that $X_{t}$ is weakly exogenous. If needed 
in (1) the $\Delta_{4} X_{t}$ terms can be replaced by $\Delta_{1} X_{t}$ variables. The parameters $\lambda_{s}$ and $\theta_{s}$ in equation (1) are seasonally varying adjustment and long-run parameters, respectively. Adjustment can be easier to achieve in some quarters, or economic agents may want to correct disequilibria faster in some seasons. In a consumption model context, the target relations may reflect seasonally varying preferences or seasonally varying availability of goods and services. Periodic cointegration requires that the $\lambda_{s}$-parameters are negative. Full periodic cointegration in (1) implies that there is adjustment towards a long-run relationship in all four quarters, whereas partial periodic cointegration implies that there is no adjustment in some quarters.

Boswijk and Franses (1995) propose a Wald test for cointegration in the PCM. Consider the following, slightly rewritten form of (1):

$$
\begin{aligned}
\Delta_{4} y_{t}= & \sum_{s=1}^{4} \mu_{s} D_{s, t}+\sum_{s=1}^{4}\left(\delta_{1 s} D_{s, t} y_{t-4}+\delta_{2 s}^{\prime} D_{s, t} X_{t-4}\right) \\
& +\sum_{j=1}^{p} \beta_{i} \Delta_{4} y_{t-j}+\sum_{i=0}^{p} \tau_{i}^{\prime} \Delta_{4} X_{t-i}+\varepsilon_{t}
\end{aligned}
$$

where $\delta_{1 s}=\lambda_{s}$ and $\delta_{2 s}=-\theta_{s}^{\prime} \lambda_{s}$ in (1). Writing $\delta_{s}=\left(\delta_{1 s}, \delta_{2 s}^{\prime}\right)^{\prime}$, the null hypothesis of no cointegration in season $s$, and the alternative hypothesis, of the Wald test are $H_{0 s}: \delta_{s}=0$ and $H_{1 s}: \delta_{s} \neq 0$ for some $s$, respectively. Now, writing $\delta=\left(\delta_{1}^{\prime}, \ldots, \delta_{4}^{\prime}\right)^{\prime}$, the null hypothesis of no cointegration in any season and the alternative hypothesis of the joint Wald test are $H_{0}: \delta=0$ and $H_{1}: \delta \neq 0$ respectively. The two Wald statistics are calculated as

$$
\begin{aligned}
\text { Wald }_{s} & =(n-k)\left(\left(R S S_{0 s}-R S S_{1}\right) / R S S_{1}\right), \\
\text { Wald } & =(n-k)\left(\left(R S S_{0}-R S S_{1}\right) / R S S_{1}\right),
\end{aligned}
$$

where $k$ is the number of estimated parameters in equation (2), and where $R S S_{1}$ is the OLS residual sum of squares from the unrestricted model and $R S S_{0 s}$ and $R S S_{0}$ the residual sums of squares under $H_{0 s}$ and $H_{0}$, respectively. The relevant critical values of the various Wald test statistics are given in Boswijk and Franses (1995). They also propose tests for various parameter restrictions when there is evidence of cointegration in two or more quarters, like tests for equality of the adjustment parameters and for the parameters concerning the long-run relationships across 
seasons. In the empirical part below we will refer to this method as the P-SE (periodic single equation) approach.

\subsection{Periodic cointegration - multiple equations}

A periodic VAR model of order 1 [PVAR(1)] of a $k$ dimensional quarterly observed vector of time series $y_{n}$ can be written as:

$$
y_{n}=\varphi_{s} y_{n-1}+u_{n},
$$

where $s=1, \ldots S, n=1, \ldots, N$ and $u_{n}$ is a vector of i.i.d. disturbances with mean zero and $E\left(u_{n} u_{n}^{\prime}\right)=\Omega_{s}$. The seasonally varying $(k \times k)$ parameter matrices $\varphi_{s}$ are of full rank and the covariance matrices $\Omega_{s}$ imply that the PVAR(1) process can have different short-run properties across quarters.

Even though all parameters are allowed to vary across the quarters, Kleibergen and Franses (1999) show that the specification (4) imposes the same long-run properties for each season. If we determine the relationship between $y_{n}$ and $y_{n-S}$, that is, the same season in the previous year, and rewrite the resulting expression in its nonseasonal annual form, see Tiao and Grupe (1980) and Osborn (1991), it becomes

$$
\Delta Y_{s, t}=\Pi_{s} Y_{s, t-1}+\varepsilon_{s, t}, \quad t=1, \ldots, T=\frac{N}{4},
$$

where

$$
\Pi_{s}=\left(\prod_{i=1}^{s} \varphi_{s-i+1} \prod_{i=1}^{S-s} \varphi_{S-i+1}\right)-I_{k} .
$$

If there is cointegration amongst the elements in $y_{n}$ then:

$$
\begin{aligned}
\Pi_{s} & =\alpha_{s} \beta_{s}^{\prime} \Longleftrightarrow \\
\varphi_{s+1} \alpha_{s} \beta_{s}^{\prime} \varphi_{s+1}^{-1} & =\alpha_{s+1} \beta_{s+1}^{\prime} .
\end{aligned}
$$

The result in (7) implies that the spaces spanned by $\alpha_{s+1}$ and $\beta_{s+1}$ are identical to the spaces spanned by $\varphi_{s+1} \alpha_{s}$ and $\varphi_{s+1}^{-1^{\prime}} \beta_{s}$.

Estimation of the cointegration parameters in $\Pi_{s}$ is not straightforward as it implies nonlinear restrictions on the $\varphi_{s}$ parameters. Kleibergen and Franses 
(1999) therefore suggest an alternative method, which amounts to optimizing a log-likelihood based objective function. This objective function can also be used to test for the number of cointegration relations. The resulting test statistic can be compared to the relevant critical values of the Johansen trace statistic, at least asymptotically. The PVAR(1) model can be extended to include unrestricted seasonally varying intercepts and trends. In the empirical part below we will denote the model with seasonally varying intercepts included as P-ME-1 (periodic multiple equation of type 1) and the model with both seasonally varying intercepts and trends as P-ME-2.

Finally, the results for the PVAR(1) model hold for higher order dynamics if we assume the following lag structure of a PVAR(p) model

$$
\begin{aligned}
y_{n} & =\varphi_{1, s} y_{n-1}+\varphi_{2, s} y_{n-5}+\ldots+\varphi_{p, s} y_{n-(p-1) S-1}+u_{n} \\
& =\varphi_{s}(1) y_{n-1}+\varphi_{1, s}^{*} \Delta_{S} y_{n-1}+\ldots+\varphi_{p-1, s}^{*} \Delta_{S} y_{n-(p-2) S-1}+u_{n},
\end{aligned}
$$

where $\varphi_{i, s}^{*}=-\sum_{j=i+1}^{p} \varphi_{j, s}, i=1, \ldots, p-1$.

\subsection{Seasonal cointegration - single equation}

Engle et al. (1993) EGHL propose a two-step test method for seasonal and nonseasonal cointegration, which is similar to the Engle and Granger (1987) test procedure for zero frequency cointegration. In the case of cointegration at all frequencies for bivariate time series the following linear combinations will be stationary processes:

$$
\begin{aligned}
& z_{1, t}=y_{1, t}-\alpha_{1} x_{1, t}, \\
& z_{2, t}=y_{2, t}-\alpha_{2} x_{2, t}, \\
& z_{3, t}=y_{3, t}-\alpha_{3} x_{3, t}-\alpha_{4} y_{3, t-1}-\alpha_{5} x_{3, t-1},
\end{aligned}
$$

where $w_{1, t}=\left(1+B+B^{2}+B^{3}\right) w_{t}, w_{2, t}=-\left(1-B+B^{2}-B^{3}\right) w_{t}$ and $w_{3, t}=$ $-\left(1-B^{2}\right) w_{t}$, for $w_{t}=x_{t}$ and $y_{t}$.

The first step involves estimating $\alpha_{1}$ to $\alpha_{5}$ in (9) using OLS, where deterministic components such as a constant, a trend and seasonal dummies may be included in these cointegration regressions. The second step amounts to checking whether the 
resulting estimated residuals $\widehat{z}_{1, t}$ to $\widehat{z}_{3, t}$ are stationary, using the following auxiliary regressions:

$$
\begin{aligned}
(1-B) \widehat{z}_{1, t} & =\pi_{1} \widehat{z}_{1, t-1}+\sum_{i=1}^{k} \gamma_{i}(1-B) \widehat{z}_{1, t-i}+\varepsilon_{t} \\
(1+B) \widehat{z}_{2, t} & =\pi_{2}\left(-\widehat{z}_{2, t-1}\right)+\sum_{i=1}^{k} \gamma_{i}(1+B) \widehat{z}_{1, t-i}+\varepsilon_{t}, \\
\left(1+B^{2}\right) \widehat{z}_{3, t} & =\pi_{3}\left(-\widehat{z}_{3, t-2}\right)+\pi_{4}\left(-\widehat{z}_{3, t-1}\right)+\sum_{i=1}^{k} \gamma_{i}\left(1+B^{2}\right) \widehat{z}_{3, t-i}+\varepsilon_{t}
\end{aligned}
$$

Cointegration at the zero and biannual frequencies implies $\pi_{1}=0$ and $\pi_{2}=0$, respectively, which is to be tested against the alternative that $\pi_{i}<0, i=1,2$ with one-sided $t$-tests. If the $F$-test for the hypothesis $\pi_{3}=\pi_{4}=0$ cannot be rejected there is evidence of cointegration at the annual frequency. The $t$-statistics for $\pi_{1}$ and $\pi_{2}$ obey the familiar Dickey-Fuller distribution and critical values can be found in Phillips and Ouliaris (1990). Critical values for the $F$-statistic are tabulated in EGHL.

If the cointegrating rank is 1 at all frequencies for a bivariate time series and $x_{t}$ is weakly exogenous, a final seasonal cointegration equation for $y_{t}$ reads as

$$
\begin{aligned}
\Delta_{4} y_{t}= & \sum_{j=0}^{q} \delta_{j} \Delta_{4} x_{t-j}+\sum_{i=1}^{p} \beta_{i} \Delta_{4} y_{t-i} \\
& +\gamma_{11} z_{1 t-1}+\gamma_{12} z_{2 t-1}-\gamma_{13} z_{3 t-2}-\gamma_{14} z_{3 t-3}+\varepsilon_{t} .
\end{aligned}
$$

For further reference, we call this model the S-SE model.

\subsection{Seasonal cointegration - multiple equations}

Lee (1992) suggests a maximum likelihood estimator for seasonal cointegration relations, based on a fully specified VAR model. This procedure extends the approach summarized in Johansen (1995). Assuming that $\Delta_{4} Y_{t}$ is stationary, where $Y_{t}$ denotes a $(k \times 1)$ vector of variables, a seasonal error correction model $[\mathrm{SECM}]$ of the following form is considered:

$$
\Delta_{4} Y_{t}=\sum_{i=1}^{4} \alpha_{i} \beta_{i}^{\prime} Z_{i, t}+\Gamma_{1} \Delta_{4} Y_{t-1}+\ldots+\Gamma_{p-4} \Delta_{4} Y_{t-p+4}+\Phi D_{t}+\varepsilon_{t}
$$

where the $D_{t}$ are deterministic components and where $\varepsilon_{t}$ is i.i.d. $N_{k}(0, \Omega)$. There is seasonal cointegration if at least one of the $\alpha_{i} \beta_{i}^{\prime}$ matrices for $i=2,3,4$ on the right 
hand side has reduced, but non-zero rank. The linear filters $Z_{i, t}$ in (12) remove all unit roots except those at the zero, biannual and annual frequencies, and they are the vector equivalents of the univariate HEGY transformations. If the matrices

$\alpha_{i} \beta_{i}^{\prime}$ have reduced rank, $\beta_{i}^{\prime} Z_{i, t}$ is stationary even though the processes $Z_{i, t}$ are nonstationary. Furthermore, the regressors $Z_{i, t}$ are asymptotically uncorrelated, that is

$$
T^{-1} \sum_{t=1}^{T} Z_{i, t} Z_{j, t}^{\prime} \stackrel{P}{\rightarrow} 0, i \neq j
$$

implying that the cointegration vectors and adjustment coefficients can be found by removing the reduced rank restriction on the other frequencies by concentrating out the associated regressors. Lee (1992) suggests the restriction $\alpha_{4} \beta_{4}^{\prime}=0$, and we label this method, with unrestricted seasonal dummies included, as S-ME-1.

Franses and Kunst (1999) argue that deterministic seasonal dummy variables, which are often included unrestrictedly in (12) to handle the deterministic part of seasonality, should be confined to the seasonal cointegrating relations instead. This is because unrestricted seasonal intercepts in the SECM may lead to diverging seasonal trends, which can be unlikely in certain practical cases. This restricted seasonal dummies case is denoted as S-ME-2.

Finally, Johansen and Schaumburg (1999) argue that the restriction $\alpha_{4} \beta_{4}^{\prime}=0$ is very strong and not justified from a theoretical point of view. They refine the asymptotic theory for the multivariate seasonal cointegration model and propose an alternative estimation procedure for the parameters corresponding to the annual frequency. In the forecasting study below we label this third method, where we again include restricted seasonal dummies, as S-ME-3.

\section{Data}

In our forecasting study we consider the logs of quarterly observed time series on consumption $(C)$ and income $(Y)$ in the United Kingdom, Sweden, (Western-) Germany, Japan, Italy and the US. The data set for UK covers the time period 1955:1 to 1989:4 (consumption on non-durables and disposable income), whereas 
the time series for Sweden ranges from the period 1963:1 to 1988:4 (consumption on non-durables and disposable income) and for Germany from 1960:1 to 1988:4 (consumption and disposable income). The data set for Japan covers the period 1961:1 to 1987:4 (total consumption and disposable income) and the data set for Italy the period 1970:1 to 1996:1 (consumption on non-durables and services and GDP). The data set for the US covers the period 1947:1 to 1991:4 (consumption on non-durables and GNP) [henceforth the $\mathrm{US}_{C, Y}$ data set].

We also examine the nominal money stock $(M 1)$ and real GNP $(Y)$ in the US for the period 1948:1 to 1985:4 [henceforth the $\mathrm{US}_{M, Y}$ data set].

These bivariate time series, have been analyzed previously in Boswijk and Franses (1995), Cubadda (1999), Engle et al. (1993), Franses and Paap (1995), Hylleberg et al. (1990), Lee and Siklos (1997) and Wells (1997). Note that we discard 16 observations at the end of each sample in order to evaluate out-of sample forecasting.

\section{Empirical Results}

In this section we first discuss the in-sample estimation results and then we turn to the out-of-sample forecasting results.

\subsection{Estimation results}

At first we have a look at the results obtained from applying HEGY tests for seasonal unit roots in univariate series. Results of the tests for seasonal and nonseasonal unit roots appear in Table 1 . The auxiliary regressions include an intercept, seasonal dummies and a deterministic trend in each case. It is clear that all variables seem to contain unit roots at the zero frequency. The results are more mixed at the seasonal frequencies. Roots at the biannual frequency are rejected for $Y$ in the German, the UK and the $\mathrm{US}_{M, Y}$ data sets and no evidence of unit roots exists at the annual frequency for consumption in Germany, Japan, Sweden. Roots at the annual frequency are also rejected for $Y$ in the German, the $\mathrm{US}_{C, Y}$ and the $\mathrm{US}_{M, Y}$ data sets. All in all, however, there is substantial evidence of changing seasonal 
patterns. We return to the seasonal unit root approach later on.

\subsubsection{Periodic cointegration models}

Results of the Wald-tests for periodic cointegration in the single equation case appear in Table 2. All the dependent variables (the consumption series and the money stock series) are transformed into fourth differences. We choose the first difference filter for $Y$ in the UK and in the $\mathrm{US}_{M, Y}$ data set. We find no evidence of periodic cointegration in the $\mathrm{US}_{C, Y}$ data, but the Wald-test statistics suggest cointegration in the first quarter in Germany, in the second quarter for Sweden and the UK and in the third quarter for Italy and for the $\mathrm{US}_{M, Y}$ data. Although the evidence of cointegration may be viewed as weak, we also proceed with the estimation of a partial PCM with cointegration in the first quarter for Japan.

Results for the final models can be found in Table 3. The first three columns correspond with estimated adjustment or error-correction terms $\widehat{\lambda}_{s}$ and the coefficients for the long run relations $\widehat{\theta}_{s}$, respectively. In all cases except for Italy we include an intercept in the long-run relation, indicated by $\widehat{\mu}$. All of these are significant at the $5 \%$ level. Comparisons with previous analysis of similar time series can be done for most cases, although we use a shorter sample period here because sixteen observations are discarded. The results for Germany are in line with the results found in Franses and Paap (1995), where they, using other cointegration methods, find evidence of cointegration between consumption and income in the first quarter only. Boswijk and Franses (1995) examine the same data series for Sweden and find cointegration in the second and fourth quarter. Furthermore, they find evidence of equal adjustment parameters, that is, $\widehat{\lambda}_{2}=\widehat{\lambda}_{4}=-0.260$ and cannot reject that $\widehat{\theta}_{2}=\widehat{\theta}_{4}=0.687$. The money equation for the US can be compared with the results found in Lee and Siklos (1997). In contrast to their findings, we find evidence of zero frequency cointegration between the nominal money stock and real GNP in the third quarter. Interestingly, these two series are also analyzed in a study by Barsky and Miron (1989), where they argue that comovements in the fourth quarter dominate and that money and output do not seem to move together in the first and 
second quarters.

We also present results of tests for weak exogeneity in Table 4. Adding the estimated cointegration relations to $\operatorname{AR}(p)$ models of suitably differenced $Y$ variables suggests that the assumption of weak exogeneity seems to be valid in all the consumption equation examples. However, as the $F$-test statistic for the cointegration variable is significant in the $\mathrm{US}_{M, Y}$ data set, a joint model for money and GNP may yield more efficient estimates of the cointegration parameters in that case.

Results using the Kleibergen and Franses (1999) approach to multiple equations periodic models are summarized in Table 5. The lag lengths are chosen according the $\mathrm{AIC}$ and $\mathrm{BIC}$ criteria, in addition to equation by equation diagnostic tests. We include seasonally varying intercepts (P-ME-1) or alternatively seasonally varying intercepts and trends (P-ME-2). In the first case we find evidence of periodic cointegration in the German and the $\mathrm{US}_{C, Y}$ data sets only. When we include seasonally varying trends in the equations there is evidence of cointegration in Japan and the $\mathrm{US}_{M, Y}$ data set as well. Critical values are based on our own simulations for small samples.

\subsubsection{Seasonal cointegration models}

The tests for seasonal cointegration using the two-step procedure proposed by EGHL are summarized in Table 6, where a constant and a trend are included in the cointegration regression if the zero frequency is considered and a constant and seasonal dummies if the seasonal frequencies are considered. There is no evidence of cointegration at the zero frequency, except between money and GNP in the US. We find no evidence of cointegration at the biannual frequency, but for the annual frequency we do so for Germany, Japan and Sweden.

EGHL analyze the consumption and income data for Japan using the same techniques but again with sixteen more observations. They argue that the absence of cointegration at the zero and biannual frequencies cannot be rejected and that a question of whether there is cointegration at the annual frequency could be answered with a weak 'maybe'. Lee and Siklos (1997) use the two-step approach to M1 and 
real GNP in the US, but their results are quite different from ours. Instead of finding evidence of cointegration at the zero and annual frequencies, as we do, they only reject the null hypothesis of no-cointegration at the biannual frequency.

Table 7 presents results for the final EGHL equations with the cointegrating relations at the annual frequency included. Columns two and three correspond to the estimated error-correction terms for the annual frequency, where only the coefficients for $z_{3 t-2}$ appear to be significant at the $5 \%$-level.

Results of tests for weak exogeneity appear in Table 8, where the estimated cointegration relations are added to univariate $\operatorname{AR}(p)$ models for $\Delta_{4} y_{t}$. The assumption of weak exogeneity seems to be valid for Germany and Sweden, but not for Japan.

Results of the maximum likelihood seasonal cointegration approach can be found in Table 9. The lag lengths are chosen using the AIC and BIC, in addition to equation by equation diagnostic tests. Lee and Siklos (1995) present critical values for all frequencies in the unrestricted seasonal intercepts case (S-ME-1). Critical values for the restricted seasonal intercept case (S-ME-2) are taken from Tables 1a1f in Franses and Kunst (1999). Finally, Johansen and Schaumburg present critical values for the annual frequency in the restricted intercept case (S-ME-3). Note that for the zero frequency case, we use the critical values tabulated in Lee and Siklos (1995) for all model specifications. For the biannual case, we use the critical values tabulated in Franses and Kunst (1999) for specifications (S-ME-2) and (S-ME-3).

Starting with the results when using unrestricted intercepts, there is evidence of cointegration at the zero frequency for the Italian, Swedish and the $\mathrm{US}_{C, Y}$ data sets. The results further suggest one cointegration vector at the biannual frequency in Germany, UK and again in the $\mathrm{US}_{C, Y}$ data set. For all countries, except for Italy, there is evidence of stationary vectors at the annual frequency, while the results for the UK even suggest two vectors at this frequency.

Turning to the case with restricted seasonal intercepts we see that there is now no evidence of cointegration at frequencies $\pi$ and $\pi / 2$ in the German data set, which is also the case when using the method proposed by Johansen and Schaumburg. The single cointegrating vector at the annual frequency in Sweden is not significant when 
using restricted seasonal intercepts in the Lee specification. The reverse result is true for the cointegrating vector at $\pi / 2$ for Japan.

If we compare these findings with the results obtained using the two-step EGHL procedure the results are quite different. We find almost no evidence of cointegration at the zero frequency and at the biannual frequency, using the EGHL approach, but we do so using multiple equation methods. However, for the annual frequency we find similar results across the two approaches.

\subsubsection{Nonseasonal models}

Finally, we include in our forecasting study two nonseasonal models. The first is a vector error correction model $[\mathrm{VECM}]$, where the cointegration relationship is estimated using the familiar Johansen maximum likelihood method. Table 10 summarizes the test results and we observe that zero frequency cointegration is found for the Italian, Swedish and $\mathrm{US}_{C, Y}$ data sets. For further reference, we will denote these models as N-ME-1. We also consider VAR models in first differences and these will be denoted as N-ME-2. In both models we include deterministic seasonal dummies.

As our interest is in evaluating out-of-sample forecasting performance, we do not present detailed estimation results. These can be obtained form the corresponding author upon request.

\subsection{Forecasting}

We now turn to a discussion of the out-of-sample forecasting exercise, where it is our aim to forecast consumption and money.

\subsubsection{Method}

In general, if we do not find any evidence of cointegration using a particular model type for a specific data set, we do not generate any forecasts. Only for the VAR model for first differences and without cointegration, that is N-ME-2, we always generate forecasts. 
To be able to compare the single equation methods with the system approaches when it comes to forecasting, we use the weak exogeneity equations for $y_{t}$, but now without the cointegration relations added. For the P-SE and S-SE methods, this approach results in a two equation system, where the first equation is presented in Table 3 for periodic cointegration case and in Table 7 for seasonal cointegration, while the second equations for the exogenous variable are presented in Tables 4 and 8 , respectively.

For the periodic VAR model, we forecast from (8) in levels with seasonally varying deterministic terms included, in case there is evidence of full rank. When there is evidence of a reduced rank, we include the seasonally varying $\Pi_{s}-$ matrices and generate forecasts from the resulting model in fourth differences, and then transform these to levels.

If we do not find any evidence of cointegration at one or two frequencies using the three versions of the multiple equation seasonal cointegration approach, we set the rank of corresponding $\Pi-$ matrices equal to zero and generate forecasts from the resulting model.

We forecast the relevant time series sixteen steps ahead. Next, the estimation period is extended by one quarter, but we do not reestimate the equations. This extension of the sample period is done fifteen times until we generate the last onestep ahead forecast error for each model and data set. This procedure leads to sixteen one-step ahead forecast errors for each model and data set, fifteen two-step ahead forecast errors and so on. In total we have 136 forecasts for each model and data set. The results are summarized by presenting values of the root mean squared prediction errors RMSPE (times 100) for one, four and eight steps ahead forecasts in tables 11, 12 and 13, respectively. In table 14, we summarize all forecast errors by considering the following RMSPE measure:

$$
\sqrt{\frac{1}{136}\left(\sum_{i=1}^{16}\left(\widehat{x}_{i 1}-x_{i 1}\right)^{2}+\ldots+\sum_{i=1}^{2}\left(\widehat{x}_{i 15}-x_{i 15}\right)^{2}+\left(\widehat{x}_{16}-x_{16}\right)^{2}\right)} .
$$

Finally, in Table 15 we summarize all results by giving the average ranks of the nine different approaches across the seven data sets. 


\subsubsection{Results}

The results in Table 11 (for one-step ahead forecast errors) and in the second column of Table 15 are quite clear. The VAR model without cointegration for the data in first differences clearly gives the best one-step ahead forecasts. The average rank of N-ME-2 is 1.7, and its closest competitor is a multiple equation seasonal cointegration model with average rank 3.2. The N-ME-2 model offers the lowest RMSPE values for 5 out of 7 data sets.

When we consider the results in Table 12 and those in the third column of Table 15, we observe that the results for one-step-ahead forecasts extend to the case of four-step ahead forecasts. Again the VAR model for first differenced data yields the best forecasts ( 2 out of 7 data sets and lowest rank), and again the seasonal cointegration methods comes as a good second. The difference between the performances of the various models become smaller, though.

The results in Table 13 and the fourth column of table 15 indicate that for longer forecast horizons, the seasonal cointegration methods (and in particular, the multiple equation method with restricted intercepts) improve upon the periodic and N-ME methods.

Finally, when we average over all forecasts as in Table 14, and the final column of Table 15, we observe that the differences between the various methods have decreased even further.

When we compare the performance of the single equation methods with that of multiple equation methods, we do not find clear-cut signs that our approach consistently outperform the other. Indeed our empirical findings suggest that for shorter horizons the nonseasonal VAR for first differenced variables is preferred, while in general (also for longer horizons) the seasonal cointegration models seem to yield the most accurate forecasts. 


\section{Concluding remarks}

We have analyzed periodic and seasonal cointegration models for bivariate quarterly observed time series in an empirical forecasting study. We included both single equation and multiple equations methods. A VAR model in first differences with and without cointegration restrictions was also included in the analysis, where it served as a benchmark. Our empirical results indicate that the VAR model in first differences is best if one-step and four-step ahead forecasts are considered. If one considers the cointegrated models only, the seasonal cointegration models are the best. This conclusions also extends to longer forecast horizons. Hence, when comparing periodic versus seasonal cointegration models, we find that the seasonal cointegration models tend to yield better forecasts. Finally, there is no clear indication that multiple equation methods improve on single equation methods. 


\section{References}

Barsky and Miron (1989) The seasonal cycle and the Business cycle. Journal of Political Economy 97: 503-535.

Boswijk HP (1994) Testing for an unstable root in conditional and structural error correction models. Journal of Econometrics 63: 37-60.

Boswijk HP, Franses PH (1995) Periodic cointegration: Representation and inference. Review of Economics and Statistics 77: 436-454.

Boswijk HP, Franses PH, Haldrup N (1997) Multiple unit roots in periodic autoregressions. Journal of Econometrics 80: 167-168.

Cubadda G (1999) Common cycles in seasonal non-stationary time series. Journal of Applied Econometrics 14: 273-291.

Dahl Pedersen I (1996) A practical implementation of the seasonal cointegration theory. Masters Thesis, University of Copenhagen.

Engle RF, Granger CWJ (1987) Co-integration and error correction: Representation, estimation and testing. Econometrica 55: 251-276.

Engle RF, Granger CWJ, Hylleberg S, Lee HS (1993) Seasonal cointegration: The Japanese consumption function. Journal of Econometrics 55: 275-298.

Franses PH (1996) Periodicity and stochastic trends in economic time series. Oxford University Press.

Franses PH and Kunst RM (1999) On the role of seasonal intercepts in seasonal cointegration. Oxford Bulletin of Economics and Statistics 61: 409-434.

Franses PH and McAleer M (1998) Cointegration analysis of seasonal time series. Journal of Economic Surveys 12 (5): 651-678.

Franses PH and Paap R (1995) Seasonality and stochastic trends in German consumption and income. Empirical Economics 20: 109-132. 
Hylleberg S, Engle RF, Granger CWJ, Yoo BS (1990) Seasonal integration and cointegration. Journal of Econometrics 44: 215-238.

Johansen S (1995) Likelihood-based inference in cointegrated vector autoregressive models. Oxford: Oxford University Press.

Johansen S and Schaumburg (1999) Likelihood analysis of seasonal cointegration. Journal of Econometrics 88: 301-339.

Kleibergen F and Franses PH (1999) Cointegration in periodic vector autoregression. Econometric institute report EI-9906/A.

Kunst RM (1993) Seasonal cointegration, common seasonals, and forecasting seasonal series. Empirical Economics 18: 761-776.

Lee HS (1992) Maximum likelihood inference on cointegration and seasonal cointegration. Journal of Econometrics 54: 1-47.

Lee HS and Siklos P (1995) A note on the critical values for the maximum likelihood (seasonal) cointegration tests. Economic Letters 49: 137-145.

Lee HS and Siklos P (1997) The role of seasonality in economic time series Reinterpreting money-output causality in U.S. data. International journal of forecasting 13: 381-391.

Osborn DR (1991) The implications of periodically varying coefficients for seasonal time series processes. Journal of Econometrics 48: 373-384.

Phillips PCB and Ouliaris S (1990) Asymptotic properties of residual based tests for cointegration. Econometrica 58: 165-193.

Reimers H-E (1997) Forecasting of seasonal cointegrated processes. International Journal of Forecasting 13: 369-380.

Tiao GC and Grupe MR (1980) Hidden periodic autoregressive-moving average models in time series data. Biometrika 67: 365-373. 
Wells JM (1997) Modelling seasonal patterns and long-run trends in US time series. International Journal of Forecasting 13: 407-420. 


\section{A Tables}

Table 1: Testing for seasonal unit roots in univariate time series.

\begin{tabular}{llllccc}
\hline \hline & & $t_{\pi_{1}}$ & $t_{\pi_{2}}$ & $F_{\pi_{3}-\pi_{4}}$ & $F_{\pi_{1}-\pi_{4}}$ & Lags \\
\hline GER & $\mathrm{C}$ & -0.50 & -1.48 & $6.66^{*}$ & 3.86 & 1 \\
& $\mathrm{Y}$ & -1.05 & $-5.15^{*}$ & 4.01 & $9.65^{*}$ & $1-2$ \\
\hline ITA & $\mathrm{C}$ & -1.63 & -1.62 & 4.43 & 4.08 & $1-5$ \\
& $\mathrm{Y}$ & -1.80 & -2.19 & 3.75 & 4.14 & $1-2$ \\
\hline JAP & $\mathrm{C}$ & -0.08 & -1.78 & $13.21^{*}$ & $7.30^{*}$ & 1,4 \\
& $\mathrm{Y}$ & 0.69 & -2.05 & 5.18 & 3.75 & 1 \\
\hline SWE & $\mathrm{C}$ & -0.76 & -2.30 & $7.79^{*}$ & 5.70 & - \\
& $\mathrm{Y}$ & -0.51 & -2.30 & 4.65 & 3.95 & - \\
\hline UK & $\mathrm{C}$ & -3.02 & -1.79 & 5.70 & 5.54 & $1,4-5$ \\
& $\mathrm{Y}$ & -1.97 & $-3.67^{*}$ & $57.6^{*}$ & $42.34^{*}$ & - \\
\hline US $C, Y$ & $\mathrm{C}$ & -0.90 & -2.20 & 4.69 & 3.98 & $1-6$ \\
& $\mathrm{Y}$ & -1.71 & -2.27 & $13.6^{*}$ & $9.10^{*}$ & $1-2$ \\
\hline $\mathrm{US}_{M, Y} Y$ & $\mathrm{M}$ & -0.11 & -2.28 & 3.07 & 2.94 & $1,4-6$ \\
& $\mathrm{Y}$ & 0.53 & $-3.33^{*}$ & $13.43^{*}$ & $9.92^{*}$ & 1,3 \\
\hline \hline
\end{tabular}

* Significant at the $5 \%$ level. Seasonal dummies and trend are included in each equation. Lags denotes the number of lagged fourth-order differences in the auxiliary test regression.

Table 2: Testing for single equation periodic cointegration (Wald-tests).

\begin{tabular}{|c|c|c|c|c|c|c|c|}
\hline \multirow[b]{2}{*}{ Quarter } & \multicolumn{5}{|c|}{ Quarter } & \multicolumn{2}{|c|}{ Lags } \\
\hline & 1 & 2 & 3 & 4 & All & $\Delta_{4} c_{t}$ & $\Delta_{q} y_{t}$ \\
\hline GER & $17.00^{*}$ & 4.82 & 5.89 & 3.11 & 19.64 & $1-5$ & 1 \\
\hline ITA & 2.98 & 7.03 & $12.49 *$ & 1.91 & 16.10 & $1-3$ & - \\
\hline JAP & 10.40 & 9.07 & 9.12 & 2.06 & 21.05 & 1,4 & 3,4 \\
\hline SWE & 6.41 & $17.52^{*}$ & 3.03 & 7.82 & 19.35 & 1,4 & - \\
\hline UK (1) & 1.26 & $12.11^{*}$ & 5.47 & 0.45 & 16.94 & 1,5 & $1-3$ \\
\hline $\mathrm{US}_{C, Y}$ & 7.47 & 3.51 & 5.81 & 4.26 & 16.75 & 1,4 & $1,3-5$ \\
\hline $\mathrm{US}_{M, Y}(1)$ & 0.35 & 1.33 & $11.79^{*}$ & 2.60 & 6.19 & $1,4-6$ & - \\
\hline
\end{tabular}

${ }^{*}$ Significant at the $5 \%$ level. $\Delta_{q} y_{t}$ and seasonal dummies are included in each equation. All dependent variables (consumption or money stock) are in seasonal differences. A (1) indicates that $q=1$ and thus the use of the first difference filter for $y_{t}$. 
Table 3: Single equation periodic cointegration models.

\begin{tabular}{r|ccc|cccccc}
\hline \hline & $\widehat{\lambda}_{s}$ & $\widehat{\mu}$ & $\widehat{\theta}_{s}$ & $\bar{R}^{2}$ & & & & & \\
& & & & $(1)$ & $(4)$ & \\
& & AR $(4)$ & ARCH & ARCH & JB \\
\hline GER, $s=1$ & $-0.47^{*}$ & $0.17^{*}$ & $1.00^{*}$ & 0.85 & 3.18 & 2.78 & 0.02 & 0.21 & 1.45 \\
ITA, $s=3$ & $-0.12^{*}$ & - & $0.94^{*}$ & 0.92 & 0.06 & 0.75 & 0.36 & 0.19 & 4.53 \\
JAP, $s=1$ & $-0.27^{*}$ & $-0.38^{*}$ & $0.92^{*}$ & 0.80 & 0.70 & 1.65 & 0.26 & 0.63 & 3.20 \\
SWE, $s=2$ & $-0.47^{*}$ & $-0.39^{*}$ & $0.72^{*}$ & 0.30 & 0.04 & 0.29 & 0.42 & 0.22 & $37.0^{*}$ \\
UK, $s=2$ & $-0.74^{*}$ & $-1.48^{*}$ & $0.85^{*}$ & 0.64 & 1.40 & 1.83 & 0.01 & 1.23 & $8.34^{*}$ \\
$\mathrm{US}_{M, Y}, s=3$ & $-0.07^{*}$ & $-1.89^{*}$ & $0.64^{*}$ & 0.90 & 1.71 & 1.00 & 2.42 & 1.00 & 1.61 \\
\hline \hline
\end{tabular}

* Significant at the $5 \%$ level. Consumption or money stock on the left hand side in the equation. AR concerns the $F$-version of the LM test for residual autocorrelation, $\mathrm{ARCH}$ is the $F$-version of the LM test for $\mathrm{ARCH}$ and $\mathrm{JB}$ is the Jarque-Bera test for normality.

Table 4: Testing for weak exogeneity in single equation periodic cointegration models.

\begin{tabular}{c|cc|cc}
\hline \hline & Lags & Deterministics & $t_{\widehat{\beta}_{z}}$ & $F_{\widehat{\beta}_{z}}$ \\
\hline GER & $1,4-5$ & I & 0.76 & 0.58 \\
ITA & $1-5$ & I & 0.87 & 0.76 \\
JAP & $1-4,7$ & I & 0.15 & 0.02 \\
SWE & $1-2$ & I & 1.20 & 1.44 \\
UK $(1)$ & 1,4 & I, SD & 1.66 & 1.36 \\
$\operatorname{US}_{M, Y}(1)$ & $1,3-5$ & I, SD & $2.18^{*}$ & $4.74^{*}$ \\
\hline \hline
\end{tabular}

* Significant at the $5 \%$ level. The test statistics are based on $\operatorname{AR}(p)$ models for independent variables in the PCM models with cointegration relations $(\mathrm{z})$ added, see Boswijk and Franses (1995) for details. A (1) indicates the use of first difference filters. Seasonal dummies were not found to be significant in the cases $Y$ is transformed into fourth differences. 
Table 5: Testing for cointegration in periodic VAR models.

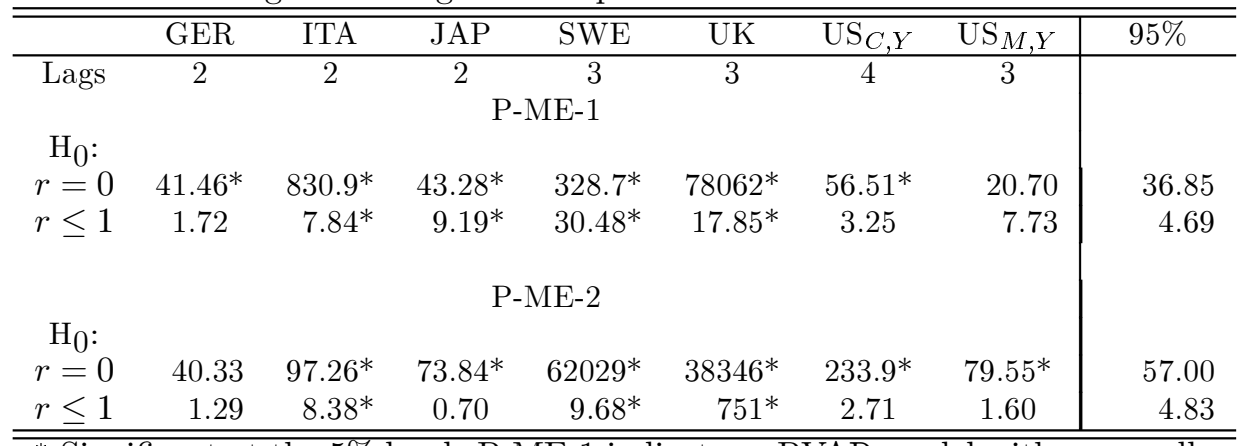

* Significant at the $5 \%$ level. P-ME-1 indicates a PVAR model with seasonally varying intercept included, while P-ME-2 indicates a PVAR model with both seasonally varying intercept and trend included. Critical values are based on our own simulations. Lags correspond to the order of the PVAR model, as described in section 2.2

Table 6: Testing for single equation seasonal cointegration.

\begin{tabular}{c|cc|cc|cc}
\hline \hline & $t_{\widehat{\pi}_{1}}$ & Lags & $t_{\widehat{\pi}_{2}}$ & Lags & $F_{\widehat{\pi}_{3} \cap \widehat{\pi}_{4}}$ & Lags \\
\hline GER & -2.18 & $1,3-5$ & -0.76 & $1-4$ & $13.3^{*}$ & 1,4 \\
ITA & -1.93 & $1-2$ & -1.17 & $1-3$ & 5.41 & $1-3$ \\
JAP & -1.83 & $1,4-5$ & -1.41 & $1-4,7$ & $17.6^{*}$ & $1-3$ \\
SWE & -3.33 & $1-2$ & -2.09 & $1-2,4$ & $14.9^{*}$ & $3-4$ \\
UK & -2.74 & $1-4$ & -1.62 & $1-2,4-6$ & 7.67 & $1,3-4$ \\
US $_{C, Y}$ & -2.64 & $1-2,4-5$ & -2.10 & $1-5$ & 4.78 & $1-2,4-5$ \\
US $_{M, Y}$ & $-3.95^{*}$ & $1,4-5$ & -1.87 & $1,4-6,9$ & 3.74 & $1-7$ \\
\hline \hline
\end{tabular}

* Significant at the $5 \%$ level. Intercept and trend are included in the cointegration regression for the zero frequency. Intercept and seasonal dummies are included in the cointegration regression for the seasonal frequencies. Lags correspond to the auxiliary regression and concern fourth order differenced variables. 
Table 7: Single equation seasonal cointegration models.

\begin{tabular}{|c|c|c|c|c|c|c|c|c|c|}
\hline & Lags & $\widehat{\gamma}_{13}$ & $\widehat{\gamma}_{14}$ & $\bar{R}^{2}$ & $\operatorname{AR}(1)$ & $\operatorname{AR}(4)$ & $\begin{array}{c}(1) \\
\text { ARCH }\end{array}$ & $\begin{array}{c}(4) \\
\text { ARCH }\end{array}$ & $\mathrm{JB}$ \\
\hline GER & $1,3-4$ & $-0.40^{*}$ & 0.06 & 0.85 & 0.36 & 0.50 & 0.34 & 0.50 & 0.22 \\
\hline JAP & 1,4 & $-0.48^{*}$ & 0.07 & 0.83 & 0.63 & 1.75 & 0.26 & 0.82 & 4.29 \\
\hline SWE & 1 & $-0.38^{*}$ & 0.12 & 0.31 & 0.32 & 2.26 & 1.45 & 0.93 & 1.83 \\
\hline
\end{tabular}

* Significant at the $5 \%$ level. An intercept and $\Delta_{4} y_{t}$ are included in each equation. AR concerns the the $F$-version of the LM test for residual autocorrelation, $\mathrm{ARCH}$ is the $F$-version of the LM test for ARCH and JB is the Jarque-Bera test for normality.

Table 8: Testing for weak exogeneity in single equation seasonal cointegration models.

\begin{tabular}{c|cc|ccl}
\hline \hline & Lags & Deterministics & $t_{\widehat{\gamma}_{13}}$ & $t_{\widehat{\gamma}_{14}}$ & $F_{\widehat{\gamma}_{13-14}}$ \\
\hline GER & $1,4-5$ & I & 0.65 & -1.22 & 0.92 \\
JAP & $1-4,7$ & I & -1.87 & $-2.35^{*}$ & $5.17^{*}$ \\
SWE & $1-2$ & I & -0.21 & $-2.02^{*}$ & 2.10 \\
\hline \hline
\end{tabular}

* Significant at the $5 \%$ level. AR $(p)$ models for independent variables in the EGHL equations with cointegration relations added, see EGHL for detailes. 
Table 9: Testing for seasonal cointegration in VAR models.

\begin{tabular}{|c|c|c|c|c|c|c|c|c|c|c|c|}
\hline \multirow[b]{2}{*}{ Frequency: } & \multirow[b]{2}{*}{ p-r } & \multicolumn{3}{|c|}{$\overline{\overline{\text { S-ME-1 }}}$} & \multicolumn{3}{|c|}{$\overline{\overline{\text { S-ME-2 }}}$} & \multicolumn{3}{|c|}{$\overline{\overline{\text { S-ME-3 }}}$} & \multirow[b]{2}{*}{ Lags } \\
\hline & & 0 & $\pi$ & $\pi / 2$ & 0 & $\pi$ & $\pi / 2$ & 0 & $\pi$ & $\pi / 2$ & \\
\hline \multirow{2}{*}{ GER } & 1 & 6.56 & $32.75^{*}$ & $22.78^{*}$ & 6.56 & 15.04 & 21.83 & 6.56 & 15.04 & 30.76 & 2 \\
\hline & 2 & 2.32 & 3.77 & 6.25 & 2.32 & 3.98 & 5.45 & 2.32 & 3.98 & 5.86 & \\
\hline \multirow[t]{2}{*}{ ITA } & 1 & $27.73^{*}$ & 11.9 & 12.36 & $27.73^{*}$ & 9.56 & 12.69 & $27.73^{*}$ & 9.56 & $40.42^{*}$ & 2 \\
\hline & 2 & 4.67 & 5.08 & 0.64 & 4.67 & 2.06 & 1.88 & 4.67 & 2.06 & 12.40 & \\
\hline \multirow[t]{2}{*}{ JAP } & 1 & 14.60 & 10.34 & $35.14^{*}$ & 14.60 & 4.80 & $27.75^{*}$ & 14.60 & 4.80 & 32.69 & 3 \\
\hline & 2 & 0.86 & 1.60 & 5.74 & 0.86 & 0.93 & 5.74 & 0.86 & 0.93 & 7.17 & \\
\hline \multirow[t]{2}{*}{ SWE } & 1 & $19.11^{*}$ & 13.71 & $24.96^{*}$ & $19.11^{*}$ & 13.50 & 25.29 & $19.11^{*}$ & 13.50 & $38.00^{*}$ & - \\
\hline & 2 & 4.35 & 3.44 & 7.39 & 4.35 & 3.63 & 7.38 & 4.35 & 3.63 & 7.76 & \\
\hline \multirow[t]{2}{*}{ UK } & 1 & 17.60 & $28.51^{*}$ & $75.37^{*}$ & 17.60 & $28.41^{*}$ & $75.29 *$ & 17.60 & $28.41^{*}$ & $108.4^{*}$ & - \\
\hline & 2 & 0.01 & 8.09 & $21.09^{*}$ & 0.01 & 8.20 & $21.03^{*}$ & 0.01 & 8.20 & $23.09^{*}$ & \\
\hline \multirow{2}{*}{$\mathrm{US}_{C, Y}$} & 1 & $28.52^{*}$ & $21.05^{*}$ & $36.75^{*}$ & $28.52^{*}$ & $20.91^{*}$ & $36.71^{*}$ & $28.52^{*}$ & $20.91^{*}$ & $84.35^{*}$ & 1 \\
\hline & 2 & 2.25 & 7.43 & 4.34 & 2.25 & 7.25 & 4.43 & 2.25 & 7.25 & $17.80^{*}$ & \\
\hline \multirow{2}{*}{$\mathrm{US}_{M, Y}$} & 1 & 10.56 & 15.97 & $28.70^{*}$ & 10.56 & 28.92 & $28.92^{*}$ & 10.56 & 28.92 & $61.03^{*}$ & 2 \\
\hline & 2 & 3.03 & 5.62 & 4.80 & 3.03 & 5.04 & 5.04 & 3.03 & 5.04 & 14.06 & \\
\hline
\end{tabular}

* Significant at the 5\% level. S-ME-1 denotes the Lee (1992) specification with unrestricted seasonal intercepts, S-ME-2 denotes the same specification with restricted seasonal intercepts, S-ME-3 denotes the Johansen and Schaumburg (1999) specification with restricted seasonal intercepts. 
Table 10: Nonseasonal models (with and without cointegration).

\begin{tabular}{|c|c|c|c|c|}
\hline & $\mathrm{p}-\mathrm{r}$ & $\begin{array}{l}\text { VECM } \\
\text { Trace }\end{array}$ & Lags & $\begin{array}{l}\text { VAR } \\
\text { Lags }\end{array}$ \\
\hline GER & $\begin{array}{l}1 \\
2\end{array}$ & $\begin{array}{r}11.70 \\
1.94\end{array}$ & 4 & 4 \\
\hline ITA & $\begin{array}{l}1 \\
2\end{array}$ & $\begin{array}{c}27.73^{*} \\
4.67\end{array}$ & 5 & 5 \\
\hline JAP & $\begin{array}{l}1 \\
2\end{array}$ & $\begin{array}{r}10.32 \\
0.39\end{array}$ & 5 & 5 \\
\hline SWE & $\begin{array}{l}1 \\
2\end{array}$ & $\begin{array}{c}19.11^{*} \\
4.35\end{array}$ & 3 & 3 \\
\hline UK & $\begin{array}{l}1 \\
2\end{array}$ & $\begin{array}{r}17.60 \\
0.01\end{array}$ & 3 & 3 \\
\hline $\mathrm{US}_{C, Y}$ & $\begin{array}{l}1 \\
2\end{array}$ & $\begin{array}{c}21.07^{*} \\
4.35\end{array}$ & 5 & 5 \\
\hline $\mathrm{US}_{M, Y}$ & $\begin{array}{l}1 \\
2\end{array}$ & $\begin{array}{r}10.83 \\
1.14\end{array}$ & 4 & 4 \\
\hline
\end{tabular}

* Significant at the $5 \%$ level. Lags are selected using $\mathrm{AIC}$ and BIC. Deterministic seasonal dummies included in each case. For the VECM we use the familiar Johansen trace test statistic for zero frequency cointegration.

Table 11: Root mean squared prediction errors: one-step ahead forecasts.

\begin{tabular}{c|ccccccc}
\hline \hline & GER & ITA & JAP & SWE & UK & US $_{C, Y}$ & US $_{M, Y}$ \\
\hline P-SE & 1.294 & 0.484 & 1.246 & 1.816 & 3.663 & - & 1.708 \\
P-ME-1 & 2.477 & 0.691 & 0.760 & 2.804 & 3.381 & 1.344 & - \\
P-ME-2 & - & 0.682 & 1.054 & $\underline{1.586}$ & 3.523 & 1.371 & 1.883 \\
\hline S-SE & 1.277 & - & 0.922 & 1.781 & - & - & - \\
S-ME-1 & 1.263 & - & 0.663 & 2.087 & 2.365 & 1.040 & 1.466 \\
S-ME-2 & - & - & 0.758 & - & 2.374 & 1.044 & 1.455 \\
S-ME-3 & - & 0.430 & - & 2.030 & 1.952 & 1.076 & 1.402 \\
\hline N-ME-1 & - & $\underline{0.395}$ & - & 2.080 & - & 1.066 & - \\
N-ME-2 & $\underline{1.135}$ & 0.432 & $\underline{0.616}$ & 1.829 & $\underline{1.878}$ & $\underline{0.793}$ & $\underline{1.201}$ \\
\hline \hline
\end{tabular}

The smallest RMSPE for each data set is underlined. 
Table 12: Root mean squared prediction errors: four-step ahead forecasts.

\begin{tabular}{c|ccccccc}
\hline \hline & GER & ITA & JAP & SWE & UK & US $_{C, Y}$ & $\mathrm{US}_{M, Y}$ \\
\hline P-SE & 2.335 & 1.899 & $\underline{0.855}$ & 1.974 & 5.971 & - & 3.890 \\
P-ME-1 & 3.170 & 1.434 & 1.178 & 4.066 & 5.244 & 2.107 & - \\
P-ME-2 & - & 1.718 & 2.225 & 2.487 & 5.710 & 1.407 & $\underline{3.342}$ \\
\hline S-SE & 2.320 & - & 1.752 & $\underline{1.402}$ & - & - & - \\
S-ME-1 & $\underline{1.788}$ & - & 1.349 & 2.065 & 4.049 & 1.454 & 3.754 \\
S-ME-2 & - & - & 1.316 & - & 4.046 & 1.453 & 3.763 \\
S-ME-3 & - & 1.493 & - & 1.993 & 3.909 & 1.678 & 3.697 \\
\hline N-ME-1 & - & $\underline{1.416}$ & - & 2.393 & - & 1.878 & - \\
N-ME-2 & 2.154 & 1.748 & 1.460 & 1.541 & $\underline{3.849}$ & $\underline{1.295}$ & 3.664 \\
\hline \hline
\end{tabular}

The smallest RMSPE for each data set is underlined.

Table 13: Root mean squared prediction errors: eight-step ahead forecasts.

\begin{tabular}{c|ccccccc}
\hline \hline & GER & ITA & JAP & SWE & UK & US $_{C, Y}$ & US $_{M, Y}$ \\
\hline P-SE & 4.302 & 3.153 & 1.712 & 2.677 & 8.791 & - & 5.603 \\
P-ME-1 & 4.244 & $\underline{2.090}$ & $\underline{1.247}$ & 4.703 & 10.92 & 3.590 & - \\
P-ME-2 & - & 3.035 & 4.298 & 3.052 & 10.29 & $\underline{1.871}$ & $\underline{4.622}$ \\
\hline S-SE & 4.536 & - & 3.282 & $\underline{2.111}$ & - & - & - \\
S-ME-1 & $\underline{3.631}$ & - & 2.801 & 3.600 & 7.822 & 2.897 & 5.110 \\
S-ME-2 & - & - & 2.736 & - & 7.819 & 2.902 & 5.103 \\
S-ME-3 & - & 2.593 & - & 3.515 & 7.648 & 3.291 & 5.130 \\
\hline N-ME-1 & - & 2.415 & - & 4.145 & - & 3.668 & - \\
N-ME-2 & 4.259 & 3.589 & 3.310 & 2.155 & $\underline{7.577}$ & 2.154 & 5.113 \\
\hline \hline
\end{tabular}

The smallest RMSPE for each data set is underlined.

Table 14: Root mean squared prediction errors: all forecasts.

\begin{tabular}{c|ccccccc}
\hline \hline & GER & ITA & JAP & SWE & UK & US $_{C, Y}$ & US $_{M, Y}$ \\
\hline P-SE & 4.022 & 3.028 & 1.680 & 2.658 & 8.224 & - & 6.176 \\
P-ME-1 & 4.050 & $\underline{2.126}$ & $\underline{1.213}$ & 4.447 & 9.143 & 3.161 & - \\
P-ME-2 & - & 2.723 & 3.950 & 2.798 & 8.311 & $\underline{1.647}$ & $\underline{3.879}$ \\
\hline S-SE & 4.254 & - & 2.987 & $\underline{2.126}$ & - & - & - \\
S-ME-1 & $\underline{3.473}$ & - & 2.749 & 3.513 & 6.733 & 2.739 & 5.757 \\
S-ME-2 & - & - & 2.738 & - & 6.734 & 2.755 & 5.756 \\
S-ME-3 & - & 2.346 & - & 3.516 & 6.572 & 3.026 & 5.765 \\
\hline N-ME-1 & - & 2.182 & - & 3.777 & - & 3.335 & - \\
N-ME-2 & 4.065 & 3.157 & 3.155 & 2.160 & $\underline{6.453}$ & 1.903 & 5.735 \\
\hline
\end{tabular}

The smallest RMSPE for each data set is underlined. 
Table 15: Average ranks of the various models (Averaged over countries and data sets).

\begin{tabular}{c|cccc}
\hline \hline Method* & 1-step & 4-step & 8-step & All steps \\
\hline P-SE & 5.0 & 4.5 & 4.2 & 3.8 \\
P-ME-1 & 5.7 & 4.8 & 4.2 & 4.3 \\
P-ME-2 & 5.2 & 4.5 & 3.8 & 3.8 \\
\hline S-SE & 3.3 & 3.3 & 3.7 & 3.7 \\
S-ME-1 & 3.3 & 3.7 & 3.5 & 3.3 \\
S-ME-2 & 3.3 & 3.5 & 3.0 & 3.5 \\
S-ME-3 & 3.2 & 3.4 & 4.0 & 4.2 \\
\hline N-ME-1 & 3.7 & 4.3 & 5.3 & 5.3 \\
N-ME-2 & 1.7 & 2.6 & 3.4 & 3.8 \\
\hline \hline
\end{tabular}

${ }^{*}$ P-SE denotes a single equation periodic cointegration model, whereas P-ME-1 and -2 concern multiple equation models (with seasonally varying intercepts and with seasonally varying intercepts and trends, respectively). $\mathrm{S}$-SE denotes a single equation seasonal cointegration model, whereas S-ME concerns multiple seasonal cointegration methods (-1 is the Lee specification with unrestricted seasonal intercepts, -2 imposes resrictions on the seasonal, and -3 is the Johansen and Schaumburg specification with restricted seasonal intercepts included). N-ME-1 is a VECM in first differences with constant seasonal dummy parameters, while N-ME-2 denotes a VAR model in first differences, also with constant seasonal dummy parameters. 